\title{
85645 - AVALIAÇÃO DA FUNCIONALIDADE, MOBILIDADE FUNCIONAL E EQUILÍBRIO ESTÁTICO DE IDOSAS RELIGIOSAS
}

\author{
Pôster - Gerontologia
}

\author{
Gisele Oltramari Meneghini / Meneghini, GO / FSG Centro Universitário da Serra Gaúcha; \\ Suéli Broenstrup Kohl / Kohl, SB / FSG Centro Universitário da Serra Gaúcha; \\ José Davi Oltramari / Oltramari, JD / FSG Centro Universitário da Serra Gaúcha; \\ Alexandra Renosto / Renosto, A / FSG Centro Universitário da Serra Gaúcha; \\ Alenia Varela Finger Minuscoli / Minuscoli, AVF / FSG Centro Universitário da Serra Gaúcha; \\ Daiane Giacomet / Giacomet, D / FSG Centro Universitário da Serra Gaúcha
}

Introdução: A expectativa de vida aumentou muito nos últimos anos, no mundo nascem mais homens do que mulheres, entretanto há uma sobrevida maior de mulheres do que de homens, algumas mulheres acabam optando pela vida religiosa, seguidas pelo instinto da vocação. Ao longo do processo de envelhecimento ocorrem mudanças físicas como perda de força muscular, resistência, equilíbrio, mobilidade funcional e funcionalidade que acarretam em uma incapacidade generalizada, aumentando o risco de quedas e o imobilismo. Materiais e métodos: Esta pesquisa tratou-se de um estudo transversal com idosas com idade igual ou maior que 60 anos, residentes em uma instituição religiosa chamada Casa Jesus Bom Pastor Caxias do Sul-RS. Utilizou-se uma ficha de avaliação para coleta de dados de identificação pessoal, características sociodemográficas e clínicas, o Timed Up and Go Test para avaliar a mobilidade funcional, o Teste de Alcance Funcional Anterior para o equilíbrio estático e Escala de Lawton para funcionalidade. Resultados: Fizeram parte da amostra 32 mulheres, com idades variando entre 63 e 90 anos, onde observou-se que as duas mulheres que apresentam condição severamente dependente em relação a funcionalidade, possuíam 82 e 84 anos, respectivamente. Já a avaliação do equilíbrio estático indicou que $40,6 \%$ das mulheres apresentaram deslocamento normal e 59,4\% deslocamento inferior a $15 \mathrm{~cm}$, indicando déficit de equilíbrio. Já com relação ao teste de mobilidade funcional, $75 \%$ apresentaram médio e alto risco de quedas. Consideração final: Conclui-se ao fim deste estudo que mulheres religiosas sofrem alterações de equilíbrio estático, de mobilidade funcional e de sua funcionalidade após os 60 anos, acarretando na diminuição da qualidade de vida e aumentando o risco de quedas. 